\section{Use of artificial tissue to practice endoscopic submucosal dissection}

Endoscopic submucosal dissection (ESD) is a complex interventional procedure involving several skills and diverse instruments. A consensus from European experts suggested that training for ESD should be performed in a stepwise approach, from knowledge sharing to hands-on ESD experience in an isolated pig stomach model or in live pigs [1]. We have previously developed realistic models to provide clinical practice for ESD in ex vivo or live pig models [2,3]. In this study, we aimed to evaluate the feasibility of using an artificial tissue in ESD training. To our knowledge, this novel approach has not been previously reported.

The artificial tissue is composed of three different layers that include a thin flexible silicone sheet and hook-and-loop fasteners. The silicone sheet is precut to represent early stage cancer in the mucosa ( $\bullet$ Fig. 1a). The hook-and-loop fasteners consist of two layers of linear fabric ( Fig. 1 b). The upper layer consists of tiny hooks and represents the submucosa, while the lower layer consists of small, hairy loops and represents muscle. When the two layers are pressed together, the hooks catch in the loops and the two layers bind temporarily. When these layers are separated by pulling or peeling the two surfaces apart using an insulated-tip knife, it mimics the process of ESD. Red strands are fixed on the lower layer to represent exposed submucosal vessels, which helps give practice in the management of bleeding ( Fig. 1 c). The artificial tissue can be

\section{Video 1}

In this video the feasibility of using an artificial tissue in endoscopic submucosal dissection (ESD) training is demonstrated. The artificial tissue is composed of three different layers and can be cut and mounted on a resinoid stomach model. The practice procedures for ESD using a dual knife, an insulated-tip (IT-2) knife, and a Coagrasper are similar to the standard protocol in humans. cut and mounted on a resinoid stomach model (LM-083; Koken Co. Ltd., Tokyo, Japan; Fig.1d,e), which has several ports where the artificial tissue can be mounted for ESD practice ( $\bullet$ Fig. 1 f).

The ESD protocol used was similar to the standard protocol in humans ( $\mathbf{F i g .} 2$ and - Video 1). The greatest advantage of this model is that it can be used for complete ESD training without the ethical issues of using live animals and provides ample opportunity for repeated practice sessions.

Endoscopy_UCTN_Code_TTT_1AO_2AG

Competing interests: None

\section{H.-Y. Wang ${ }^{1,2}$, S.-C. Shih ${ }^{1,2}$, \\ C.-Y. Hung ${ }^{1,3}$, T.-Y. Shieh ${ }^{1,3}$, \\ Y.-B. Chen ${ }^{1,3}$, M.-J. Chen', 2,3}

${ }^{1}$ Division of Gastroenterology, Mackay Memorial Hospital and Mackay Medicine, Nursing and Management College,

Taipei, Taiwan

2 Mackay Medical College, New Taipei, Taiwan

${ }^{3}$ Clinical Skills Training Center, Department of Medical Education, Mackay Memorial Hospital, Taipei, Taiwan
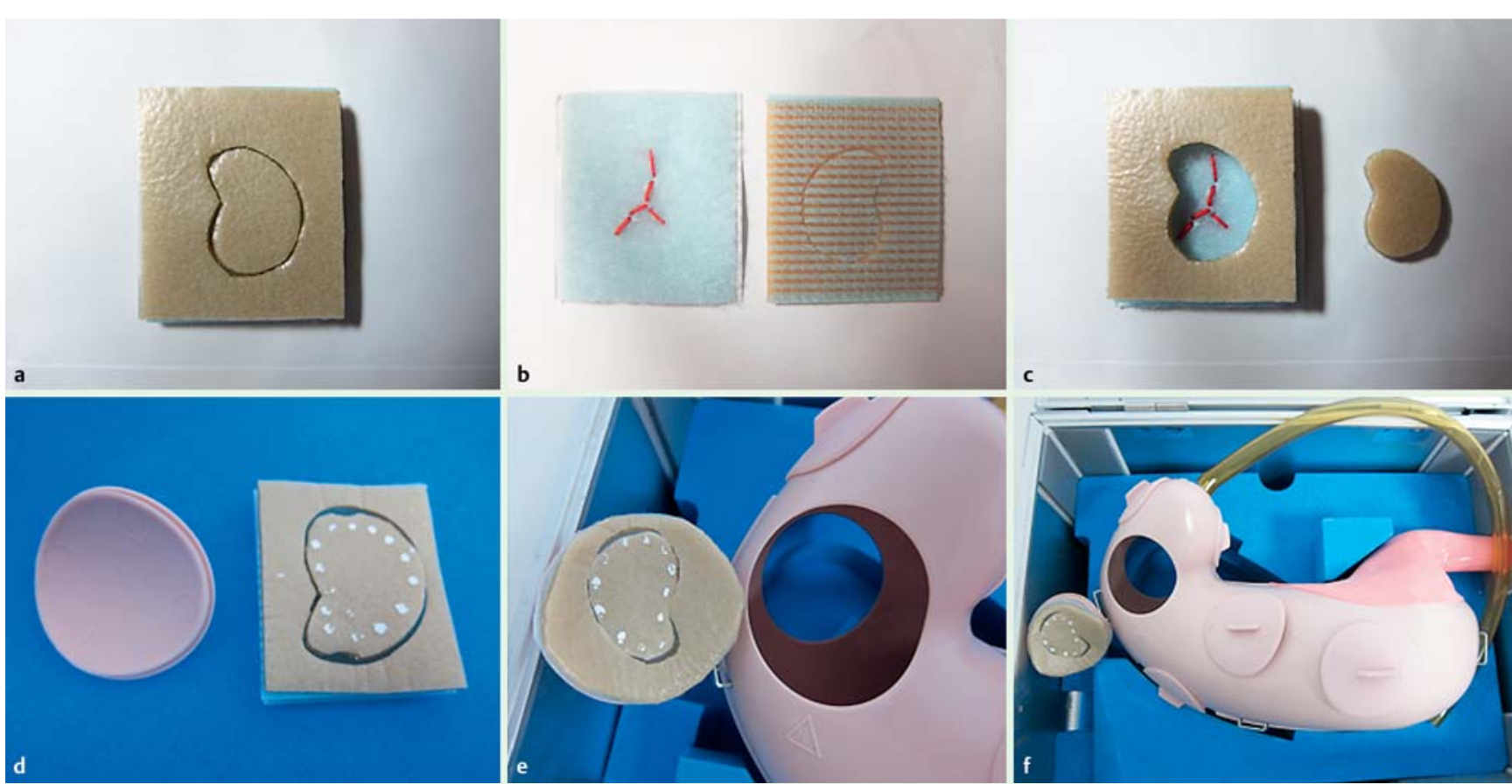

Fig. 1 Components of the artificial tissue model for the practice of endoscopic submucosal dissection (ESD). a The silicone sheet, which is precut to represent early stage cancer in the mucosa. $\mathbf{b}$ The hook-and-loop fasteners, which consist of two layers of linear fabric. $\mathbf{c}$ Red strands fixed on the lower layer represent exposed submucosal vessels, which aid practice for the management of bleeding. $\mathbf{d}, \mathbf{e}$ The artificial tissue can be cut and mounted onto a resinoid stomach model. $\mathbf{f}$ The resinoid stomach model has several ports where the artificial tissue can be mounted for ESD practice. 


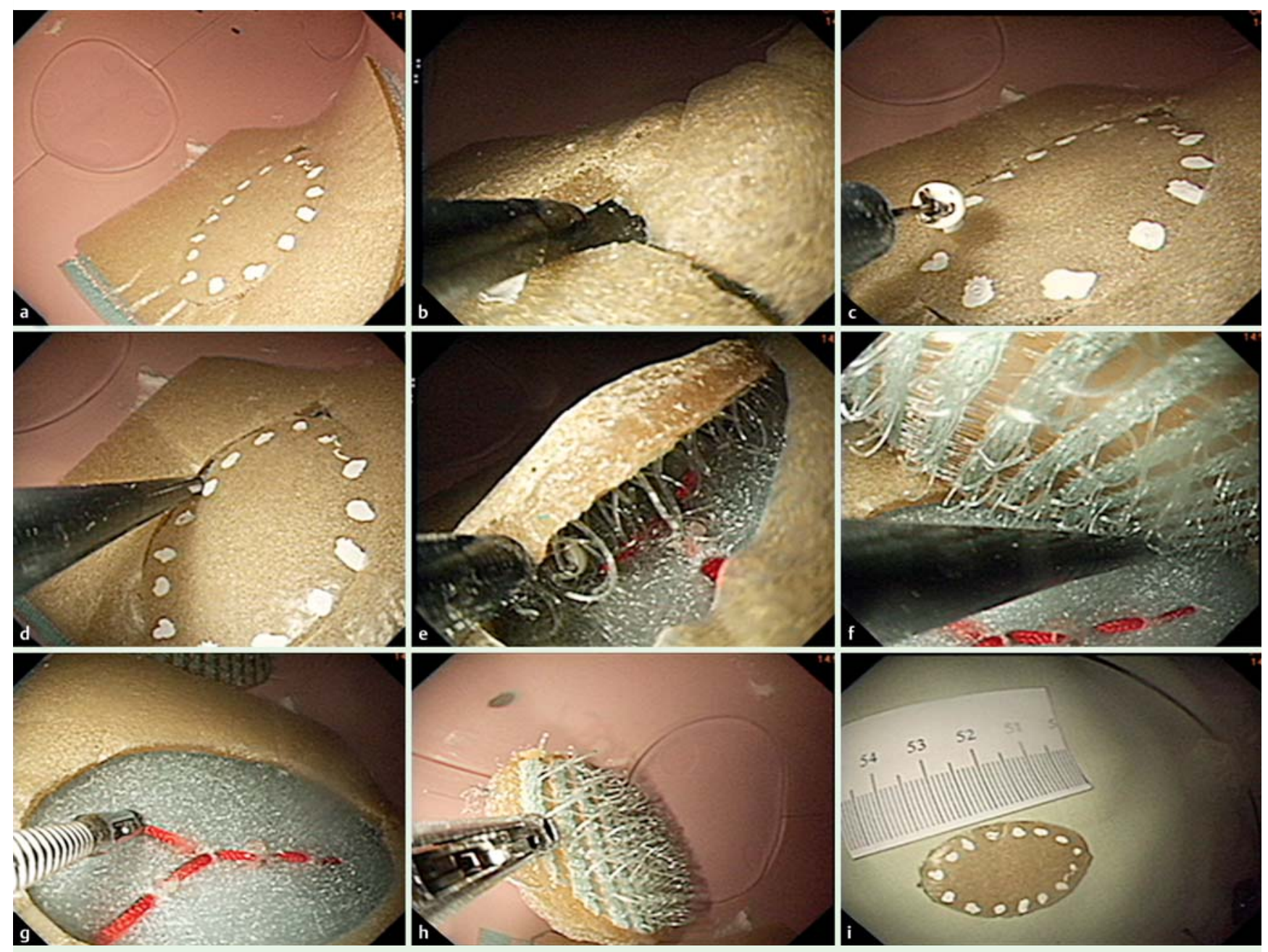

Fig. 2 The practice procedures for endoscopic submucosal dissection (ESD). a A dual knife (KD-650Q; Olympus Optical Co. Ltd., Tokyo, Japan) is used to place marks at the periphery of the lesion. $\mathbf{b}$ The mucosa outside the markings is first cut with the dual knife; then $\mathbf{c}, \mathbf{d}$ an incision is made around the circumference; and $\mathbf{e}, \mathbf{f}$ the dissection is performed using the insulated-tip (IT-2) knife (KD-610L; Olympus Optical Co. Ltd.). g The Coagrasper (FD-410LR; Olympus Optical Co. Ltd.) is used when visible vessels or bleeding are observed. $\mathbf{h}, \mathbf{i}$ The target lesion is then resected and removed from the model.

\section{References}

1 Deprez PH, Bergman JJ, Meisner S et al. Current practice with endoscopic submucosal dissection in Europe: position statement from a panel of experts. Endoscopy 2010; 42: 853-858

2 Wang TE, Wang HY, Lin CC et al. Simulating a target lesion for endoscopic submucosal dissection training in an ex vivo pig model. Gastrointest Endosc 2011; 74: 398 - 402

3 Chen MJ, Liu CY, Chen CJ et al. Simulating target lesion for endoscopic submucosal dissection training in live pig model. Endoscopy 2012; 44: E300 -E301
Bibliography

Dol http://dx.doi.org/

10.1055/s-0032-1326497

Endoscopy 2013; 45: E175-E176

(C) Georg Thieme Verlag KG

Stuttgart · New York

ISSN 0013-726X

\author{
Corresponding author

\section{M.-J. Chen, MD} \\ Division of Gastroenterology, \\ Department of Internal Medicine \\ Mackay Memorial Hospital \\ No. 92, Sec. 2, Chungshan North Road \\ Taipei \\ Taiwan \\ Fax: +886-2-25433642 \\ mingjen.ch@msa.hinet.net
}

